\title{
Laser treatment of port-wine stains
}

This article was published in the following Dove Press journal:

Clinical, Cosmetic and Investigational Dermatology

12 January 2015

Number of times this article has been viewed

\author{
Lori A Brightman' \\ Roy G Geronemus' \\ Kavitha K Reddy ${ }^{2}$ \\ 'Laser and Skin Surgery Center \\ of New York, New York, NY, USA; \\ ${ }^{2}$ Department of Dermatology, \\ Boston University School of \\ Medicine, Boston, MA, USA
}

Correspondence: Kavitha K Reddy Department of Dermatology, Boston University School of Medicine, 609 Albany St, Boston, MA 02118, USA Tel +l 6178724652

Email kreddy@bu.edu
Abstract: Port-wine stains are a type of capillary malformation affecting $0.3 \%$ to $0.5 \%$ of the population. Port-wine stains present at birth as pink to erythematous patches on the skin and/or mucosa. Without treatment, the patches typically darken with age and may eventually develop nodular thickening or associated pyogenic granuloma. Laser and light treatments provide improvement through selective destruction of vasculature. A variety of vascular-selective lasers may be employed, with the pulsed dye laser being the most common and well studied. Early treatment produces more optimal results. Advances in imaging and laser treatment technologies demonstrate potential to further improve clinical outcomes.

Keywords: laser, port-wine stain, capillary vascular malformation, vascular birthmark, selective photothermolysis, photodynamic therapy, intense pulsed light

\section{Introduction}

Capillary malformations (CMs), also called port-wine stains, appear as congenital pink to erythematous patches affecting $0.3 \%-0.5 \%$ of the population. ${ }^{1}$ There is no sex predilection, and the inheritance pattern is generally sporadic. The most common locations are the head and neck, particularly the V1 and V2 dermatomes. The trunk and extremities are also frequently affected. The color change results from an increased hemoglobin content in the skin, due to dilated capillaries and postcapillary venules in the affected regions. ${ }^{1}$ A somatic activating mutation in the GNAQ gene (c.548G $\rightarrow$ A, p.R183Q), encoding the guanine nucleotide binding protein G-alpha-q subunit, has been discovered in port-wine stain lesions. ${ }^{2}$ This appears to produce activation of extracellular signal-regulated kinase (ERK), c-Jun N-terminal kinase, and P70 ribosomal S6 kinase. ${ }^{3}$ Dysregulation of angiogenic signaling has been observed to underlie CM pathology. ${ }^{4}$ Unlike vascular tumors, CMs do not exhibit proliferation, but rather demonstrate chronic progressive vascular dilatation over the course of years.

Laser treatment of CMs reduces the likelihood and severity of unwanted associated effects, including cutaneous hypertrophy, disfigurement of the normal tissue architecture (Figure 1), development of associated pyogenic granuloma, and psychosocial morbidity. ${ }^{5}$ When treatment is sought, vascular-selective lasers represent the treatment of choice (Table 1). Using the principle of selective photothermolysis, the affected cutaneous blood vessels can be destroyed with effective and durable results while protecting the remainder of the skin. ${ }^{6}$ In this article, we review the diagnosis and medical evaluation of port-wine stains and discuss both classic and recent research findings relating to lasers and lights in producing optimal treatment outcomes. 


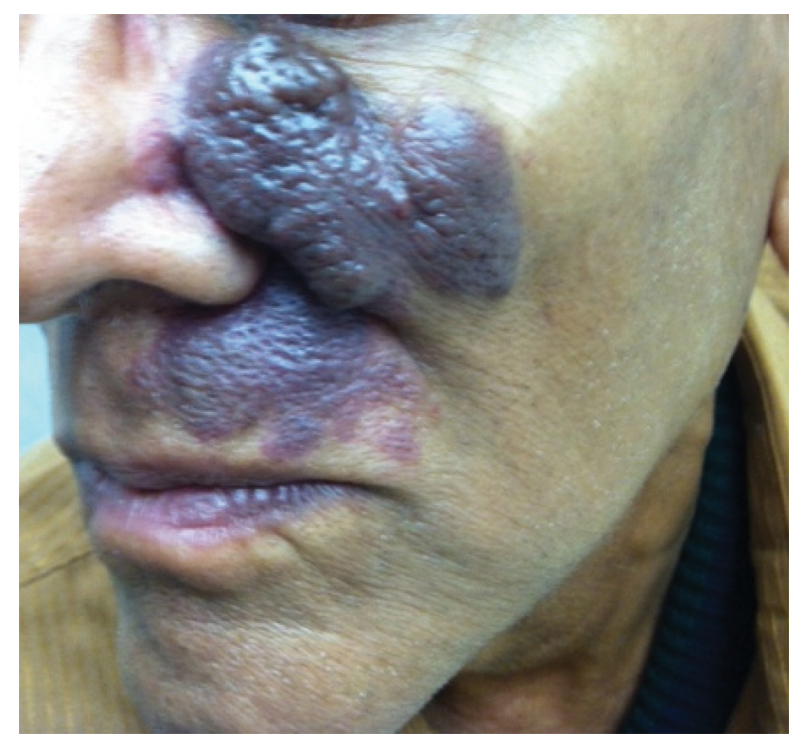

Figure I An untreated facial capillary malformation (port-wine stain) in a 60-yearold man who presented with a complaint of progressive darkening and development of nodularity in his adult years.

\section{Medical evaluation of CMs}

CMs are diagnosed clinically by physical examination revealing a pink to erythematous patch or series of patches along with a confirmatory history of presence at birth and possible gradual darkening and thickening over the course of many years. Pink patches presenting in a neonate must be observed for signs of growth during infancy, which may suggest an alternative diagnosis of infantile hemangioma rather than $\mathrm{CM}^{7}$

Medical evaluation of CMs includes screening for glaucoma when the V1 distribution of the facial nerve is affected, as up to $10 \%$ of patients may have the condition. ${ }^{8}$ Additionally, when the V1 dermatome is affected, screening for Sturge-Weber syndrome is warranted. Sturge-Weber syndrome risk is $7 \%-28 \%$ in reported studies of children with V1 CMs. ${ }^{9}$ Magnetic resonance imaging is a preferred screening modality. ${ }^{9}$ Sturge-Weber syndrome consists of a constellation of findings including facial CM, vascular involvement of the leptomeninges, possible glaucoma of the ipsilateral eye, and possible seizures or mental retardation. ${ }^{2}$ The diagnosis may be made by imaging showing classic tram-like calcifications in the brain, which may not appear until later infancy.

CMs associated with significant tissue hypertrophy or with bony hypertrophy may have increased vascular flow (Klippel-Trenaunay syndrome). ${ }^{10}$ An associated arteriovenous malformation may further be present (KlippelTrenaunay-Weber syndrome). Patients with a CM located in a midline lumbar location should also be screened for an underlying arteriovenous malformation as seen in Cobb syndrome. ${ }^{11}$

Visual examination of CM thickness and of patient skin type aids in preoperative assessment for laser treatment.

Table I Vascular-selective lasers for treatment of CMs (also called port-wine stains)

\begin{tabular}{|c|c|c|c|c|}
\hline Laser/light source & Wavelength (nm) & $\begin{array}{l}\text { Epidermal cooling } \\
\text { mechanism }\end{array}$ & $\begin{array}{l}\text { Skin } \\
\text { phototypes }\end{array}$ & Comments \\
\hline Argon & $488-514$ & None & I-III & $\begin{array}{l}\text { First-generation laser; increased rate of scarring; } \\
\text { has largely fallen out of use }\end{array}$ \\
\hline Krypton & $520-530$ & None & I-III & $\begin{array}{l}\text { First-generation laser; increased rate of scarring; } \\
\text { has largely fallen out of use }\end{array}$ \\
\hline $\begin{array}{l}\text { Frequency-doubled Nd:YAG; } \\
\text { potassium titanyl phosphate }\end{array}$ & 532 & $\begin{array}{l}\text { Contact cooling or } \\
\text { other }\end{array}$ & I-III & $\begin{array}{l}\text { Studied primarily for resistant and residual CMs; } \\
\text { can represent initial treatment choice }\end{array}$ \\
\hline $\begin{array}{l}\text { Copper bromide/ } \\
\text { copper vapor }\end{array}$ & 578 & None & I-III & $\begin{array}{l}\text { First-generation lasers; increased rate of scarring; } \\
\text { have largely fallen out of use }\end{array}$ \\
\hline Pulsed dye laser (PDL) & $585-595$ & Cryogen spray cooling & I-IV & $\begin{array}{l}\text { Most commonly used and most well studied; } \\
\text { gold standard for pediatric vascular birthmarks }\end{array}$ \\
\hline Alexandrite & 755 & Cryogen spray cooling & I-IV & Primarily for dark or resistant CMs \\
\hline Diode & $800-940$ & $\begin{array}{l}\text { Cryogen spray cooling } \\
\text { or other }\end{array}$ & I-IV & $\begin{array}{l}\text { May be used for CMs; more common for hair } \\
\text { removal, venous lakes, endovenous ablation }\end{array}$ \\
\hline Nd:YAG & 1,064 & Cryogen spray cooling & $\mathrm{I}-\mathrm{VI}$ & $\begin{array}{l}\text { Primarily for dark or resistant CMs; increased } \\
\text { penetration depth; less absorption by melanin; } \\
\text { increased risk of ulceration or scarring }\end{array}$ \\
\hline Intense pulsed light & $\begin{array}{l}390-1,200 ; \text { modifiable } \\
\text { using filters }\end{array}$ & Variable; gel & I-IV & $\begin{array}{l}\text { Less effective than laser treatment; may be } \\
\text { preferred by patients for non-purpuric treatment }\end{array}$ \\
\hline $\begin{array}{l}\text { Photodynamic } \\
\text { therapy }\end{array}$ & $\begin{array}{l}\text { Varies; optimally matched } \\
\text { to photosensitizer peak } \\
\text { absorption wavelength }\end{array}$ & $\begin{array}{l}\text { Typically not needed; } \\
\text { fan optional }\end{array}$ & $\mathrm{I}-\mathrm{VI}$ & $\begin{array}{l}\text { Less commonly used; typically intravenous } \\
\text { injection of photosensitizer with photosensitivity } \\
\text { persisting for days to weeks; good-to-excellent } \\
\text { results when compared to PDL }\end{array}$ \\
\hline
\end{tabular}

Abbreviations: CM, capillary malformation; Nd:YAG, neodymium-doped yttrium aluminum garnet; PDL, pulsed dye laser. 
Modern imaging technologies including optimal coherence tomography can aid in assessment of target vessel depth and diameters. ${ }^{12}$ Three-dimensional photography and reflectance spectrophotometry can provide objective quantification of pre- and post-procedure volume and color, respectively. ${ }^{13,14}$ In pediatric patients, an assessment of the child's ability to tolerate laser treatment in the office using topical anesthesia as needed and staff assistance, or the need for general anesthesia, is also important for preoperative preparation and planning.

\section{Treatment principles}

Laser treatment of CMs is based on selective photothermolysis of the affected vessels. Selective photothermolysis is the process by which a pigmented target absorbs photons, becoming heated and ultimately destroyed, while surrounding structures are relatively spared. ${ }^{6}$ In the case of CM, the desired targets are 10-500 $\mu \mathrm{m}$ dilated capillaries and postcapillary venules in the papillary and reticular dermis. ${ }^{12}$ The endothelium is indirectly destroyed through targeting of the chromophore in its interior, hemoglobin. Hemoglobin absorbs light strongly at 400-600 $\mathrm{nm}$ and displays reduced absorption at 700-1,100 $\mathrm{nm}$. Vascular-selective laser wavelengths are absorbed by hemoglobin, producing heat, photocoagulation and aggregation of erythrocytes, and, ultimately, necrosis of the endothelial cells. ${ }^{15}$ The vessel may rupture, producing purpura. ${ }^{16}$ In order to limit damage to surrounding structures, the pulse duration should be set at less than or equal to the target vessels' thermal relaxation time (TRT; for CM vessels, TRT is estimated at $0.45-10 \mathrm{~ms}){ }^{6,17}$

After laser treatment produces thermolysis of the vessel walls, a neutrophilic and lymphocytic infiltrate with vasculitislike karyorrhexis appears by 24 hours. Vascular remodeling occurs during the healing process, with a resulting reduction in the number and size of CM vessels. ${ }^{18,19}$ Vessels that are not sufficiently damaged may recover. Antiangiogenic agents such as topical rapamycin applied after laser treatment have been shown to reduce angiogenic signals and have shown potential to improve clinical outcomes. ${ }^{20}$

Laser treatment should be initiated early in infancy, if possible, when better outcomes are produced. ${ }^{21}$ The young dermis allows for more optimal targeting of vessels, as dermal thickness and scatter increase with age. The goal clinical endpoint during laser therapy is a transient gray to blue discoloration of the skin that evolves into purpura. Laser treatment is generally continued every 2 to 4 weeks until a plateau is reached, so that further improvement is not seen. ${ }^{7}$ The majority of patients will have more than 50\% lightening of their CMs. ${ }^{7}$ Suboptimal response remains a significant obstacle observed in $20 \%-46 \%$ of patients, and $14 \%-40 \%$ have been reported to show minimal to no response, for diverse reasons. ${ }^{22}$ Multiple treatments are the norm, and most patients require eight to ten treatments or more for optimal results. ${ }^{7}$ Some anatomic sites respond more than others, with distal or acral and centrofacial sites showing less response. ${ }^{23}$ In addition, smaller CMs generally show more complete clearance than large $\mathrm{CMs}^{24}$

\section{Laser types and treatment}

The pulsed dye laser (PDL) represents the most commonly used laser for treatment of CMs and has the most published literature supporting its use. First-generation PDLs introduced in the 1980s produced light at $577 \mathrm{~nm}$, while modern-generation PDLs produce 595-600 nm light that has a greater depth of penetration. ${ }^{22}$ There is absorption by oxyhemoglobin and deoxyhemoglobin, as well as by melanin. Common initial fluences are $8-9 \mathrm{~J} / \mathrm{cm}^{2}$ with increases until the clinical endpoint is reached. Pulse durations can be varied from 0.45 to $40 \mathrm{~ms}$ and spot sizes also come in wide variations, from 2 to $12 \mathrm{~mm}$, with circular and elliptical shape options. Cryogen spray cooling provides epidermal protection and has aided in the excellent safety record in the published literature. ${ }^{25}$ Studies show 50\%-90\% overall clearance, with approximately $10 \%$ improvement per treatment session (Figure 2). ${ }^{26}$ Improved fading is visualized when treatment is begun at an earlier age. ${ }^{7,21}$ Pigmentary changes have been reported at rates of $1.4 \%$, atrophic scarring at $4.3 \%$, and hypertrophic scarring at $0.7 \%$, generally in appropriately selected patients. ${ }^{7}$ PDL has been utilized with an excellent safety profile in skin phototypes I-III. In a study of 75 subjects of skin phototypes IV and V, PDL demonstrated improvement in CMs with frequent transient hyperpigmentation (30\%, typically lasting 6-8 weeks) and two cases of scarring that were felt to be related to pulse stacking. ${ }^{27}$ Very small and deep vessels are less likely to respond to PDL treatment. ${ }^{28}$ While PDL represents the standard initial laser treatment for CMs, a reported $20 \%-30 \%$ of CMs show resistance. ${ }^{28}$ Resistant or deep CMs are sometimes treated with alternative lasers in an effort to enhance clearance.

Frequency-doubled neodymium-doped yttrium aluminum garnet (Nd:YAG) and potassium titanyl phosphate lasers produce $532 \mathrm{~nm}$ green light. ${ }^{29}$ Because of absorption by melanin, use is primarily in skin phototypes I-III and, sometimes, skin phototype IV. ${ }^{29}$ With a limited penetration depth due to the shorter wavelength, these lasers have been primarily successful in treating superficial vascular lesions including some $\mathrm{CMs} ;{ }^{29}$ 

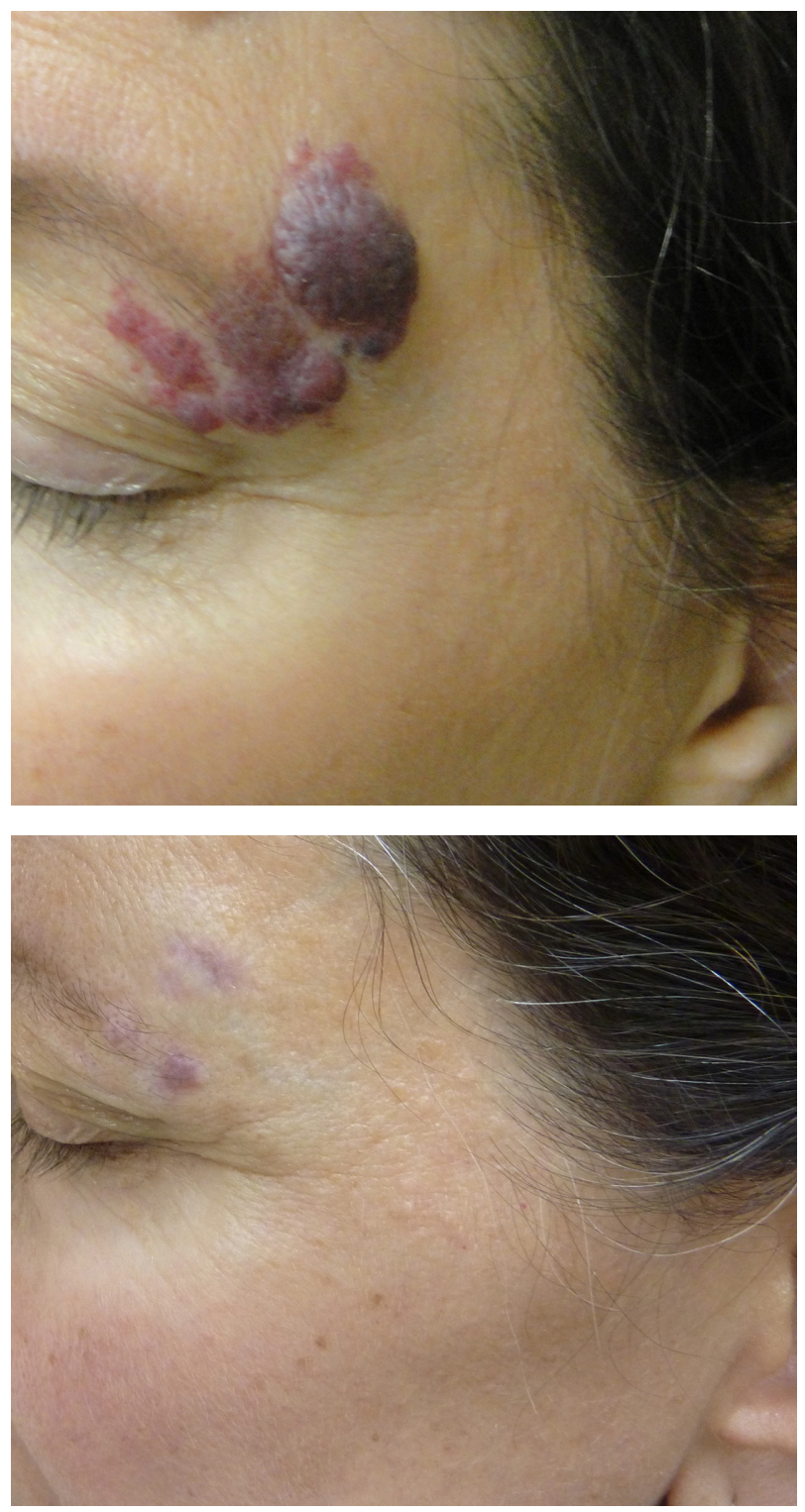

Figure 2 An adult woman with a previously untreated capillary malformation at the left temple that had developed darkening and nodularity.

Notes: The capillary malformation is shown before treatment $(\mathbf{A})$ and with excellent improvement after two sessions of pulsed dye laser (B).

$532 \mathrm{~nm}$ lasers have demonstrated improvement when treating both previously untreated and treatment-resistant $\mathrm{CMs}$ (Figure 3). ${ }^{30}$ A prospective study confirmed up to $75 \%$ improvement in color and histologic destruction of vessels in flat, nonhypertrophic CMs using a frequency-doubled $532 \mathrm{~nm}$ laser. ${ }^{18}$ In a study of 30 treatment-resistant CMs treated with one to four sessions of $532 \mathrm{~nm}$ laser, $53 \%$ showed greater than $25 \%$ improvement and $17 \%$ showed more than $50 \%$ improvement. $^{31}$ Pençe et al studied 89 patients with CMs who were treated with $532 \mathrm{~nm}$ frequency-doubled Nd:YAG laser and found $13 \%$ to have an excellent response, $38 \%$ a good response, $44 \%$ a moderate response, and $5 \%$ mild improvement. ${ }^{32}$ Some
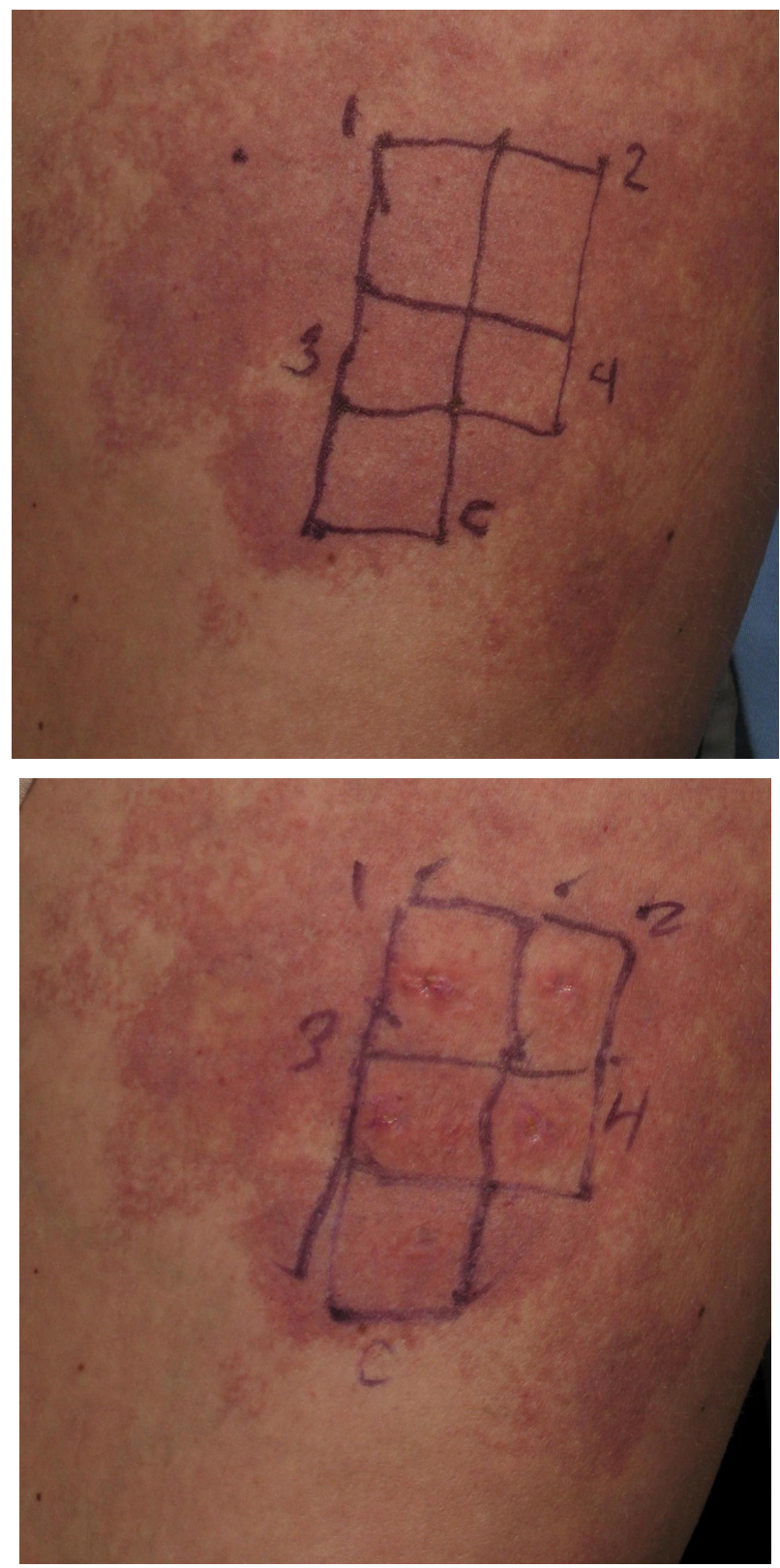

Figure 3 A previously untreated capillary malformation (port-wine stain) at the right thigh.

Notes: The capillary malformation is shown before treatment $(\mathbf{A})$ and after one session of $532 \mathrm{~nm}$ potassium titanyl phosphate laser treatment (B). Area $C$ is an untreated control; quadrants $\mathrm{I}-4$ were treated at $6-9 \mathrm{~J} / \mathrm{cm}^{2}, 6-8 \mathrm{~mm}, 3-4 \mathrm{~ms}$, with $5^{\circ} \mathrm{C}$ sapphire contact cooling. Scars are present at biopsy sites.

studies report slightly reduced efficacy per session when compared with PDL and an increased rate of side effects, including crusting. ${ }^{33}$

Alexandrite lasers fall in the near-infrared category, having a $755 \mathrm{~nm}$ wavelength. With a $50 \%-75 \%$ increased depth of penetration, near-infrared laser use for $\mathrm{CMs}$ is primarily for dark or resistant lesions. ${ }^{34} \mathrm{~A}$ retrospective study of 20 patients with either hypertrophic or PDL-resistant CMs treated with alexandrite laser alone or in combination 
with other lasers such as PDL showed most had a moderate response, while some had mild or no response. ${ }^{35}$ Diode lasers (800-940 nm) may similarly be used to treat CMs, though they are more often used for venous lakes or for endovenous ablation. ${ }^{36,37}$

Nd:YAG lasers have the highest depth of penetration of the vascular-selective lasers and the lowest epidermal melanin absorption. Because higher fluences are generally required, rates of pigmentary change and scarring are higher than with PDL in published studies $(0 \%-4.3 \%) .{ }^{38}$ Epidermal cooling is typically by cryogen spray cooling and provides an important measure of protection. Nd:YAG lasers are typically reserved for $\mathrm{CMs}$ in patients with skin phototypes $\mathrm{V}-\mathrm{VI}$ or for hypertrophied or resistant CMs. In addition, they have shown efficacy in treating vascular blebs associated with $\mathrm{CM} .{ }^{39}$ In a retrospective study of $130 \mathrm{CM}$ patients treated with long-pulsed 1,064 nm Nd:YAG laser, 2\%, 15\%, 64\%, and $19 \%$ of patients experienced $<25 \%, 25 \%-49 \%, 50 \%-75 \%$, and $>75 \%$ lesion clearance, respectively. ${ }^{40}$ Darker CMs showed more response than lighter $\mathrm{CMs}^{40} \mathrm{Nd}$ :YAG laser treatment at $1,064 \mathrm{~nm}$ has also been demonstrated to improve hypertrophy, with good-to-excellent improvements seen in the majority of the 32 studied patients. Adverse effects were more frequent, however, with hypopigmentation seen in 14 and scars in seven of the 32 subjects. ${ }^{41}$

Argon lasers were the earliest common vascular laser, used frequently in the 1970s and 1980s. ${ }^{42}$ However, they have fallen out of use with the development of more modern and safe laser systems. Argon laser light is blue-green with a 488-514 nm wavelength. Oxyhemoglobin absorbs well at this range. ${ }^{42}$ A small spot size limits the depth of penetration to $1-2 \mathrm{~mm}$ and is inconvenient for treatment. There is a high rate of hypertrophic scarring due to the continuous wave or quasi-continuous wave nature, and reports of $20 \%$ or more risk of hyper- or hypopigmentation, due to competitive absorption by epidermal melanin. ${ }^{42}$

Copper vapor and copper bromide lasers produce yellow $578 \mathrm{~nm}$ light. Krypton lasers produce green, quasi-continuous $520-530 \mathrm{~nm}$ light or yellow $568 \mathrm{~nm}$ light. The copper and krypton lasers are also early-generation vascular lasers that are largely unused due to similar complications of quasicontinuous laser exposure and absorption by melanin. ${ }^{43}$

Intense pulsed light does not meet the definition of a laser and instead produces non-coherent, broadband light between 390 and 1,200 nm using a xenon flashlamp..$^{44} \mathrm{~A}$ low fluence output is produced. When laser treatment is not available or when non-purpuric treatment with limited side effects is desired, and with the understanding that there is typically significantly reduced efficacy in comparison to laser treatment, intense pulsed light may be considered as an alternative treatment method. Cutoff filters are available to modulate the wavelength range applied. ${ }^{7}$ Spot sizes vary from $8 \times 15 \mathrm{~mm}$ to $15 \times 35 \mathrm{~mm}$ and can be further modified using opaque white paper. Typical settings may include a $550 \mathrm{~nm}$ filter, $50-75 \mathrm{~J} / \mathrm{cm}^{2}$ fluence, and 40-60 ms pulse delay. Despite the low fluence, significant pigmentary changes and adverse effects can occur, and similar cautions must be applied as with laser treatment. ${ }^{7}$

Photodynamic therapy (PDT) represents an alternative and advancing treatment option for port-wine stains. ${ }^{22}$ A chemical photosensitizer is introduced, typically via intravenous injection, and the affected area is irradiated with light of a wavelength absorbed by the photosensitizer. In the presence of oxygen, free radical damage results, with subsequent destruction of endothelial cells. ${ }^{22}$ One significant drawback is the side effect of generalized photosensitivity requiring photoprotection for days to weeks, depending on the half-life of the photosensitizer used. ${ }^{45}$ PDT treatment has been used alone or has been combined with other laser and light therapies in small studies. ${ }^{46}$ In general, studies have suggested an equivalent or possibly superior efficacy when compared to the standard PDL treatment. ${ }^{22}$ Indocyanine green photosensitizer activated by diode laser demonstrated efficacy in a study of 15 patients as an alternative to PDL. ${ }^{46}$ PDT treatment using hemoporfin and copper laser was recently studied in children 3 to 10 years of age and showed a higher rate of excellent response than the traditional PDL treatment (25\% versus $11 \%) .{ }^{47}$ A more significant difference was seen in violaceous lesions than in those that were erythematous. ${ }^{47}$ PDT treatment of port-wine stains represents an emerging arena, and investigators continue to explore optimization of treatment protocols. ${ }^{48}$

\section{Side effects and potential complications}

The most common side effects of laser treatment of CMs are redness, swelling, and bruising. Erythema (redness) and swelling persist for hours, and sometimes up to days or weeks. CMs are usually treated at settings which induce purpura (bruising) for more effective results. Purpura typically fades over 1-2 weeks. Blistering and crusting can also develop, more commonly after overlapping or double pulses. Crusted or blistered areas should be treated gently with liberal petroleum jelly and moist bandaging until healed.

More permanent effects can occur as well. Alopecia can occur when using lasers that also target melanin in areas that have pigmented hairs. Hyperpigmentation and 
hypopigmentation can occur from damage to melanosomes and/or due to postinflammatory changes. Selection of the appropriate laser wavelength matched to the patient skin type, use of epidermal cooling, more conservative fluences and pulse durations, and test spots, along with photoprotection before and after treatments, reduce the incidence of pigmentary changes. Scarring is uncommon, but must be carefully guarded against. Special attention should be paid to any areas of erosions, blisters, or necrotic skin that can develop into scars.

Ocular risks, which include corneal burns or retinal pigment loss resulting in blindness, are rare when diligent safety procedures are practiced. Appropriate eye protection includes the routine use of external eye shields. Nd:YAG and other deep-penetrating lasers may induce retinal damage in the periorbital area and are utilized most safely outside of the orbital rim. ${ }^{49}$ When lasers are used inside of the orbital rim, intraocular eye protection is paramount. ${ }^{49}$

Flammability is also a risk with the use of lasers. ${ }^{50}$ Water-based lubricants protect hairs from being singed. When treating patients under anesthesia or requiring supplemental oxygen, use of a laryngeal mask airway with clear tubing and wet draping is preferred to reduce the risk of ignition. ${ }^{50}$

\section{Conclusion and future directions}

Modern laser treatments, at wavelengths and settings matched well to individual patient and lesional characteristics, are able to produce significant diminution of CMs. Improvements of $80 \%-90 \%$ are frequently seen with early and optimal treatment. Adjuvant and novel treatments have been briefly explored in the literature and are likely to expand in coming years. The use of antiangiogenic drugs, photodynamic therapy, and other methods of targeting dilated capillaries and of limiting revascularization after laser treatment are likely to produce further improvements. Enhancements in laser technology and epidermal protection methods will also allow more complete results to be obtained while reducing risks of pigmentary changes or scarring. Importantly, an improved understanding of the molecular, genetic, and cellular changes causing this localized capillary and venular dilatation may provide a permanent cure or preventive solution.

\section{Disclosure}

Drs Reddy and Brightman have served as investigators for Syneron/Candela, Cutera, and Cynosure. Dr Brightman serves on the medical advisory board of Cynosure and has received honoraria from Syneron/Candela. Dr Geronemus has served on the medical advisory boards for Zeltiq, Syneron/Candela, and Cynosure; as an investigator for
Syneron/Candela, Cynosure, Cutera, Medicis, Allergan, Dusa, Myoscience, MoMelan, Lithera, Kythera, Miramar, Pfizer, and Cytrellis; and has been a stockholder of Zeltiq and OnLight Sciences. The authors report no other conflicts of interest in this work.

\section{References}

1. Cordoro KM, Speetzen LS, Koerper MA, Frieden IJ. Physiologic changes in vascular birthmarks during early infancy: mechanisms and clinical implications. J Am Acad Dermatol. 2009;60(4):669-675.

2. Shirley MD, Tang H, Gallione CJ, et al. Sturge-Weber syndrome and port-wine stains caused by somatic mutation in GNAQ. N Engl J Med. 2013;368(21):1971-1979.

3. Tan W, Chernova M, Gao L, et al. Sustained activation of c-Jun $\mathrm{N}$-terminal and extracellular signal-regulated kinases in port-wine stain blood vessels. J Am Acad Dermatol. 2014;71:964-968.

4. Laquer VT, Hevezi PA, Albrecht H, Chen TS, Zlotnik A, Kelly KM. Microarray analysis of port wine stains before and after pulsed dye laser treatment. Lasers Surg Med. 2013;45(2):67-75.

5. Geronemus RG, Ashinoff R. The medical necessity of evaluation and treatment of port-wine stains. J Dermatol Surg Oncol. 1991;17(1): 76-79.

6. Anderson RR, Parrish JA. Selective photothermolysis: precise microsurgery by selective absorption of pulsed radiation. Science. 1983;220(4596):524-527.

7. Astner S, Anderson RR. Treating vascular lesions. Dermatol Ther. 2005; 18(3):267-281.

8. Iwach AG, Hoskins HD Jr, Hetherington J Jr, Shaffer RN. Analysis of surgical and medical management of glaucoma in Sturge-Weber syndrome. Ophthalmology. 1990;97(7):904-909.

9. Melancon JM, Dohil MA, Eichenfield LF. Facial port-wine stain: when to worry? Pediatr Dermatol. 2012;29(1):131-133.

10. Stier MF, Glick SA, Hirsch RJ. Laser treatment of pediatric vascular lesions: port wine stains and hemangiomas. J Am Acad Dermatol. 2008;58(2):261-285.

11. Jessen RT, Thompson S, Smith EB. Cobb syndrome. Arch Dermatol. 1977;113(11):1587-1590.

12. Liu G, Jia W, Nelson JS, Chen Z. In vivo, high-resolution, threedimensional imaging of port wine stain microvasculature in human skin. Lasers Surg Med. 2013;45(10):628-632.

13. Frigerio A, Bhama PK, Tan OT. Quantitative three-dimensional assessment of port-wine stain clearance after laser treatments. Lasers Surg Med. 2013;45(10):633-638.

14. Halachmi S, Azaria R, Inbar R, Ad-El D, Lapidoth M. Use of reflectance spectrophotometry to predict the response of port wine stains to pulsed dye laser. Lasers Med Sci. 2014;29(1):225-230.

15. Heger M, Beek JF, Moldovan NI, van der Horst CM, van Gemert MJ. Towards optimization of selective photothermolysis: prothrombotic pharmaceutical agents as potential adjuvants in laser treatment of port wine stains. A theoretical study. Thromb Haemost. 2005;93(2):242-256.

16. Suthamjariya K, Farinelli WA, Koh W, Anderson RR. Mechanisms of microvascular response to laser pulses. J Invest Dermatol. 2004;122(2): $518-525$.

17. Shafirstein G, Bäumler W, Lapidoth M, Ferguson S, North PE, Waner M. A new mathematical approach to the diffusion approximation theory for selective photothermolysis modeling and its implication in laser treatment of port-wine stains. Lasers Surg Med. 2004;34(4):335-347.

18. Reddy KK, Brauer JA, Idriss MH, et al. Treatment of port-wine stains with a short pulse width 532-nm Nd:YAG laser. J Drugs Dermatol. 2013;12(1):66-71.

19. Jia W, Sun V, Tran N, et al. Long-term blood vessel removal with combined laser and topical rapamycin antiangiogenic therapy: implications for effective port wine stain treatment. Lasers Surg Med. 2010;42(2): $105-112$. 
20. Gao L, Phan S, Nadora DM, et al. Topical rapamycin systematically suppresses the early stages of pulsed dye laser-induced angiogenesis pathways. Lasers Surg Med. 2014;46(9):679-688.

21. Ashinoff R, Geronemus RG. Flashlamp-pumped pulsed dye laser for port-wine stains in infancy: earlier versus later treatment. J Am Acad Dermatol. 1991;24(3):467-472.

22. Chen JK, Ghasri P, Aguilar G, et al. An overview of clinical and experimental treatment modalities for port wine stains. J Am Acad Dermatol. 2012;67(2):289-304.

23. Lanigan SW. Port wine stains on the lower limb: response to pulsed dye laser therapy. Clin Exp Dermatol. 1996;21(2):88-92.

24. Yohn JJ, Huff JC, Aeling JL, Walsh P, Morelli JG. Lesion size is a factor for determining the rate of port-wine stain clearing following pulsed dye laser treatment in adults. Cutis. 1997;59(5):267-270.

25. Seukeran DC, Collins P, Sheehan-Dare RA. Adverse reactions following pulsed tunable dye laser treatment of port wine stains in 701 patients. Br J Dermatol. 1997;136(5):725-729.

26. Koster PH, van der Horst CM, Bossuyt PM, van Gemert MJ. Prediction of portwine stain clearance and required number of flashlamp pumped pulsed dye laser treatments. Lasers Surg Med. 2001;29(2):151-155.

27. Thajudheen CP, Jyothy K, Priyadarshini A. Treatment of port-wine stains with flash lamp pumped pulsed dye laser on Indian skin: a six year study. J Cutan Aesthet Surg. 2014;7(1):32-36.

28. Savas JA, Ledon JA, Franca K, Chacon A, Nouri K. Pulsed dye laserresistant port-wine stains: mechanisms of resistance and implications for treatment. Br J Dermatol. 2013;168(5):941-953.

29. Becher GL, Cameron H, Moseley H. Treatment of superficial vascular lesions with the KTP 532-nm laser: experience with 647 patients. Lasers Med Sci. 2014;29(1):267-271.

30. Woo WK, Jasim ZF, Handley JM. Evaluating the efficacy of treatment of resistant port-wine stains with variable-pulse 595-nm pulsed dye and 532-nm Nd:YAG lasers. Dermatol Surg. 2004;30(2 Pt 1):158-162; discussion 162.

31. Chowdhury MM, Harris S, Lanigan SW. Potassium titanyl phosphate laser treatment of resistant port-wine stains. Br J Dermatol. 2001;144(4): 814-817.

32. Pençe B, Aybey B, Ergenekon G. Outcomes of $532 \mathrm{~nm}$ frequencydoubled Nd:YAG laser use in the treatment of port-wine stains. Dermatol Surg. 2005;31(5):509-517.

33. Landthaler M, Hohenleutner U. Laser therapy of vascular lesions Photodermatol Photoimmunol Photomed. 2006;22(6):324-332.

34. Izikson L, Anderson RR. Treatment endpoints for resistant port wine stains with a $755 \mathrm{~nm}$ laser. J Cosmet Laser Ther. 2009;11(1):52-55.

35. Izikson L, Nelson JS, Anderson RR. Treatment of hypertrophic and resistant port wine stains with a $755 \mathrm{~nm}$ laser: a case series of 20 patients. Lasers Surg Med. 2009;41(6):427-432.

36. Wall TL, Grassi AM, Avram MM. Clearance of multiple venous lakes with an 800-nm diode laser: a novel approach. Dermatol Surg. 2007;33(1):100-103.
37. Van Den Bos RR, Neumann M, De Roos KP, Nijsten T. Endovenous laser ablation-induced complications: review of the literature and new cases. Dermatol Surg. 2009;35(8):1206-1214.

38. McGill DJ, MacLaren W, Mackay IR. A direct comparison of pulsed dye, alexandrite, KTP and Nd:YAG lasers and IPL in patients with previously treated capillary malformations. Lasers Surg Med. 2008;40(6): 390-398.

39. Brauer JA, Geronemus RG. Single-treatment resolution of vascular blebs within port wine stains using a novel 1,064-nm neodymiumdoped yttrium aluminum garnet laser. Dermatol Surg. 2013;39(7): 1113-1115.

40. Zhong SX, Liu YY, Yao L, et al. Clinical analysis of port-wine stain in 130 Chinese patients treated by long-pulsed 1064-nm Nd: YAG laser. J Cosmet Laser Ther. 2014;16(6):279-283.

41. van Drooge AM, Bosveld B, van der Veen JP, de Rie MA, Wolkerstorfer A. Long-pulsed $1064 \mathrm{~nm} \mathrm{Nd:YAG} \mathrm{laser} \mathrm{improves} \mathrm{hypertrophic} \mathrm{port-wine}$ stains. J Eur Acad Dermatol Venereol. 2013;27(11):1381-1386.

42. Geronemus RG. Argon laser for the treatment of cutaneous lesions. Clin Dermatol. 1995;13(1):55-58.

43. Nouri K, Alster T, Choudhary S, Falto-Aizpurua LA, Ballard CJ, Vejjabhinanta V. Laser Treatment of Acquired and Congenital Vascular Lesions [webpage on the Internet]. New York, NY: Medscape [updated October 9, 2013]. Available from: http://emedicine.medscape.com/ article/1120509-overview. Accessed October 1, 2014

44. Piccolo D, Di Marcantonio D, Crisman G, et al. Unconventional use of intense pulsed light. Biomed Res Int. 2014;2014:618206.

45. Kimel S, Svaasand LO, Kelly KM, Nelson JS. Synergistic photodynamic and photothermal treatment of port-wine stain? Lasers Surg Med. 2004;34(2):80-82.

46. Klein A, Bäumler W, Buschmann M, Landthaler M, Babilas P. A randomized controlled trial to optimize indocyanine green-augmented diode laser therapy of capillary malformations. Lasers Surg Med. 2103; 45(4):216-224.

47. Zhang B, Zhang TH, Huang Z, Li Q, Yuan KH, Hu ZQ. Comparison of pulsed dye laser (PDL) and photodynamic therapy (PDT) for treatment of facial port-wine stain (PWS) birthmarks in pediatric patients. Photodiagnosis Photodyn Ther. Epub June 25, 2014.

48. Wang Y, Zuo Z, Liao X, Gu Y, Qiu H, Zeng J. Investigation of photodynamic therapy optimization for port wine stain using modulation of photosensitizer administration methods. Exp Biol Med (Maywood). 2013;238(12):1344-1349.

49. Hammes S, Augustin A, Raulin C, Ockenfels HM, Fischer E. Pupil damage after periorbital laser treatment of a port-wine stain. Arch Dermatol. 2007;143(3):392-394.

50. Waldorf HA, Kauvar NB, Geronemus RG, Leffel DJ. Remote fire with the pulsed dye laser: risk and prevention. J Am Acad Dermatol. 1996;34(3):503-506.
Clinical, Cosmetic and Investigational Dermatology

\section{Publish your work in this journal}

Clinical, Cosmetic and Investigational Dermatology is an international, peer-reviewed, open access, online journal that focuses on the latest clinical and experimental research in all aspects of skin disease and cosmetic interventions. All areas of dermatology will be covered; contributions will be welcomed from all clinicians and

\section{Dovepress}

basic science researchers globally. This journal is indexed on CAS. The manuscript management system is completely online and includes a very quick and fair peer-review system, which is all easy to use. Visit http://www.dovepress.com/testimonials.php to read real quotes from published authors. 